\title{
MARCADORES MOLECULARES EM ESTUDOS DE CARACTERIZAÇÃO DE ERVA-MATE (Ilex paraguariensis St.Hil.): O SABOR
}

\author{
MOLECULAR MARKERS IN ERVA-MATE (Ilex paraguariensis araguariensis St.Hil.) \\ CHARACTERIZATION STUDIES: THE TASTE
}

\author{
Mario Angelo Vidor ${ }^{1}$ César Pérez Ruiz ${ }^{2}$ Santiago Vázquez Moreno ${ }^{3}$ Paulo Alfonso Floss ${ }^{4}$
}

RESUMO

A Epagri (Empresa de Pesquisa Agropecuária e Extensão Rural de Santa Catarina S.A) possui uma das maiores coleções brasileiras de erva-mate (Ilex paraguariensis St.Hil.). A partir de ensaios agronômicos preliminares, apresentaram destaque as procedências Barão de Cotegipe e Água Doce. Dentre essas, verificaram-se diferentes sabores (mais amargo e menos amargo), aparentemente, em função do tipo de folha (CLcurta e larga; LE - longa e estreita). O objetivo deste trabalho foi $o$ de tentar associar os padrões obtidos mediante marcadores moleculares, com as procedências ou acessos e características fenotípicas desejáveis - altura de planta, diâmetro de copa, densidade folhar, sobrevivência das plantas e comportamento de rebrota -, dentro do caráter sabor em erva-mate. Para isto, utilizaram-se marcadores moleculares que amplificam DNA, do tipo RAPD (Random Amplified Polymorphic DNA). Os resultados indicaram não ser possível, com o número de iniciadores utlizados como marcadores moleculares, definir geneticamente o caráter sabor, ainda que os mesmos tenham indicado tendência para tal.

Palavras-chave: Ilex paraguariensis, marcadores moleculares, variabilidade genética, PCR, RAPD, DNA biotecnologia.

\section{SUMMARY}

The Santa Catarina State Agricultural Research and Extensios Organization - Epagri SA, owns one of the largest Brazilian colletions or erva-mate (Ilex paraguariensis St.Hil.). Preliminary agronomic trials identified two promissing erva-mate materials named Barão de Cotegipe and Água Doce. Different tastes within each material were also identified, i.e. tastes with different grades of bitterness, apparently associated with the shape of leaves (CL - short and wide; LE - long and narrow). This study aimed to associate this plant patterns using molecular markers with plant origins and desirable fenotipic characteristics such as plant height, crown diameter, leaf density, plant survival, regrowth behaviour, within each taste group. For this molecular markers which amplify DNA of RAPD type (Random Amplified Polimorphic DNA) was used. The results did not allow, with the number of starters used as molecular markers, the genetic definition of the caracter taste, even though the results suggested so.

Key words: Ilex paraguariensis, molecular markers, genetic variability, PCR, RAPD, DNA, biothecnology.

\section{INTRODUÇÃO}

A erva-mate (Ilex paraguariensis St.Hil.) é uma planta endêmica do Continente Americano e se situa entre as latitudes de $21^{\circ}$ e $30^{\circ} \mathrm{S}$ e longitude entre 48 $38^{\prime}$ e $56^{\circ} 10^{\prime} \mathrm{W}$. Em condições naturais, pode ultrapassar os $60 \mathrm{~cm}$ de diâmetro e os $20 \mathrm{~m}$ de altura. É uma espécie dióica, entomófila, florescendo entre os meses de setembro e dezembro, tendo a maturação de seus frutos entre janeiro e abril (DA CROCE et al.,1994).

Com suas folhas e ramos, prepara-se uma bebida tônica e estimulante, conhecida como mate,

\footnotetext{
${ }^{1}$ Engenheiro Agrônomo, PhD, pesquisador da Empresa de Pesquisa Agropecuária e Extensão Rural de Santa Catarina (Epagri), Estação Experimental de Lages, CP 181, 88502-970, Lages/SC. E-mail: vidor@epagir .rct-sc.br. Autor para correspondência.

${ }^{2}$ Biólogo, PhD, Professor e Chefe do Departamento de Biologia Vegetal da Escuela Tecnica Superior de Ingenieros Agrónomos da Universidad Politécnica de Madrid/España.

${ }^{3}$ Engenheiro Agrônomo, PhD, Professor do Departamento de Biología Vegetal da Escuela Tecnica Superior de Ingenieros Agrónomos da Universidad Politécnica de Madrid/España.

${ }^{4}$ Engenheiro Florestal, MsC, pesquisador da Epagri, SC, Centro de Pesquisas para Pequenas Propriedades, Chapecó.
} Recebido para publicação em 22.03.01. Aprovado em 05.09.01 
chimarrão ou tererê. Além disso, apresenta muitas qualidades medicinais e nutricionais. Sua importância sócioeconômica está no fato de ser uma das espécies que sofre pouco com as oscilações do clima, comparando-se com os cultivos agrícolas em geral. Por esta razão, passou a ser uma espécie de grande importância na fixação do homem ao campo.

Atualmente, no Brasil, não existem cultivares definidas e, portanto, não há uniformidade de produção e de características qualitativas. Em estudos preliminares da EPAGRI (Empresa de Pesquisa Agropecuária e Extensão Rural de Santa Catarina SA), através do Centro de Pesquisa para Pequenas Propriedades (CPPP) de Chapecó/SC, foi verificado que árvores com diferentes formas de folhas, também apresentavam distinto sabor em sua infusão, o que é melhor aceito ou não, em função das exigências do mercado de consumo. A caracterização genética, mediante o uso de marcadores moleculares de DNA, poderá oferecer algumas informações mais estáveis quanto a este caráter fenotípico. Uma vez que o fenótipo é a expressão do genótipo em condições ambientais específicas, este pode mudar com o ambiente. No entanto, o genótipo ou a constituição do DNA de um indivíduo se mantém durante o ciclo de vida. Selecionar um fenótipo é perseguir uma meta móvel, que muda com o ambiente. A seleção com base no genótipo do indivíduo pode evitar este problema.

$$
\text { Marcadores moleculares são }
$$

características de DNA que diferenciam dois ou mais indivíduos e que serão herdadas geneticamente. Os diferentes tipos de marcadores moleculares hoje disponíveis, diferenciam-se pela tecnologia utilizada para revelar variabilidade em nível de DNA. A análise de RAPD (Random Amplified Polymorphic DNA) é baseada na amplificação termocíclica de DNA, usando uma gama de oligonucleotídeos como iniciadores (WILLIAMS $\boldsymbol{e t}$ al., 1991). A análide de RAPD é rápida, fácil, não utiliza radioisótopos e requer uma quantidade mínima de DNA, da ordem de nanogramas. Na busca da caracterização genética, alguns trabalhos têm sido desenvolvidos usando-se enzimas (WINGE $\boldsymbol{e t} \boldsymbol{a l}$., 1995) e proteínas de reserva (GREGIANINI, 1999), algumas vezes, não tão estáveis.

O objetivo deste estudo foi o de associar os padrões obtidos mediante marcadores moleculares com as procedências e características fenotípicas desejáveis - altura de planta, diâmetro de copa, densidade folhar, sobrevivência das plantas e comportamento de rebrota (FLOSS,1994) -, dentro do caráter sabor em plantas de erva-mate para facilitar o agrupamento de genótipos e a planificação dos cruzamentos. Para isto, foram utilizados marcadores moleculares que amplificam o DNA, do tipo RAPD (Random Amplified Polymorphic DNA).

\section{MATERIAL E MÉTODOS}

\section{Material vegetal}

Foram utilizadas folhas jovens de árvores silvestres de erva-mate para a extração do DNA, proveniente, numa primeira fase, de distintas partes da região sul do Brasil, com características fenotípicas desejáveis, como altura de planta, diâmetro de copa, densidade folhar, sobrevivência das plantas e comportamento de rebrota. Os materiais ou acessos (5 repetições com 400 plantas cada - 16 procedências com 25 plantas - , num total de 2000 plantas) foram cultivados no CPPP da EPAGRI em Chapecó/SC e, destes, escolheram-se, novamente, os melhores acessos quanto a estes mesmos caracteres fenotípicos, servindo de fonte de material vegetal para este ensaio. Foi utilizado DNA genômico para as reações.

As amostras foram divididas em plantas de folhas longas e estreitas (LE) de números de 1 a 30, e plantas com folhas curtas e largas (CL) ou "periquitas" de números de 1 a 25. Esta explicação é válida para as figuras 1 e 2 . A divisão deveu-se ao fato de que, dependendo do tipo de folha, o sabor da infusão oriunda destas folhas, apresentava sabor diferente. Esta informação tem origem na degustação do mate por parte das pessoas que o consomem. As amostras na figura 3, relativa ao dendograma, são representadas da seguinte forma: o número corresponde ao número da amostra e as duas letras seguintes, ao tipo de folha. Como exemplo, 01LE seria amostra 1 com folha longa e estreita; 01CL seria amostra 1 com folha curta e larga.

\section{Extração e isolamento do DNA}

O protocolo de extração de DNA utilizado neste ensaio (FERREIRA \& GRATTAPAGLIA, 1995; VIDOR \& BELÓ, 2000) se caracterizou por utilizar o detergente catiônico CTAB (cationic hexadecyl trimethyl ammonium bromide) no tampão de extração (FERREIRA \& GRATTAPAGLIA, 1995), e apresentou cinco distintas etapas. Na primeira, macerou-se o material vegetal com ajuda de um almofariz e nitrogênio líquido. $\mathrm{Na}$ segunda etapa, o material vegetal foi resuspenso num tampão de extração com um detergente, antioxidante, EDTA e agente tamponante. Na terceira etapa, esta suspensão foi submetida a uma extração com um solvente orgânico, clorofórmio-álcool isoamílico. Na quarta etapa, foi adicionado álcool (etanol) na fase aquosa para precipitação do DNA. Na quinta, o precipitado DNA/RNA foi resuspenso em um 


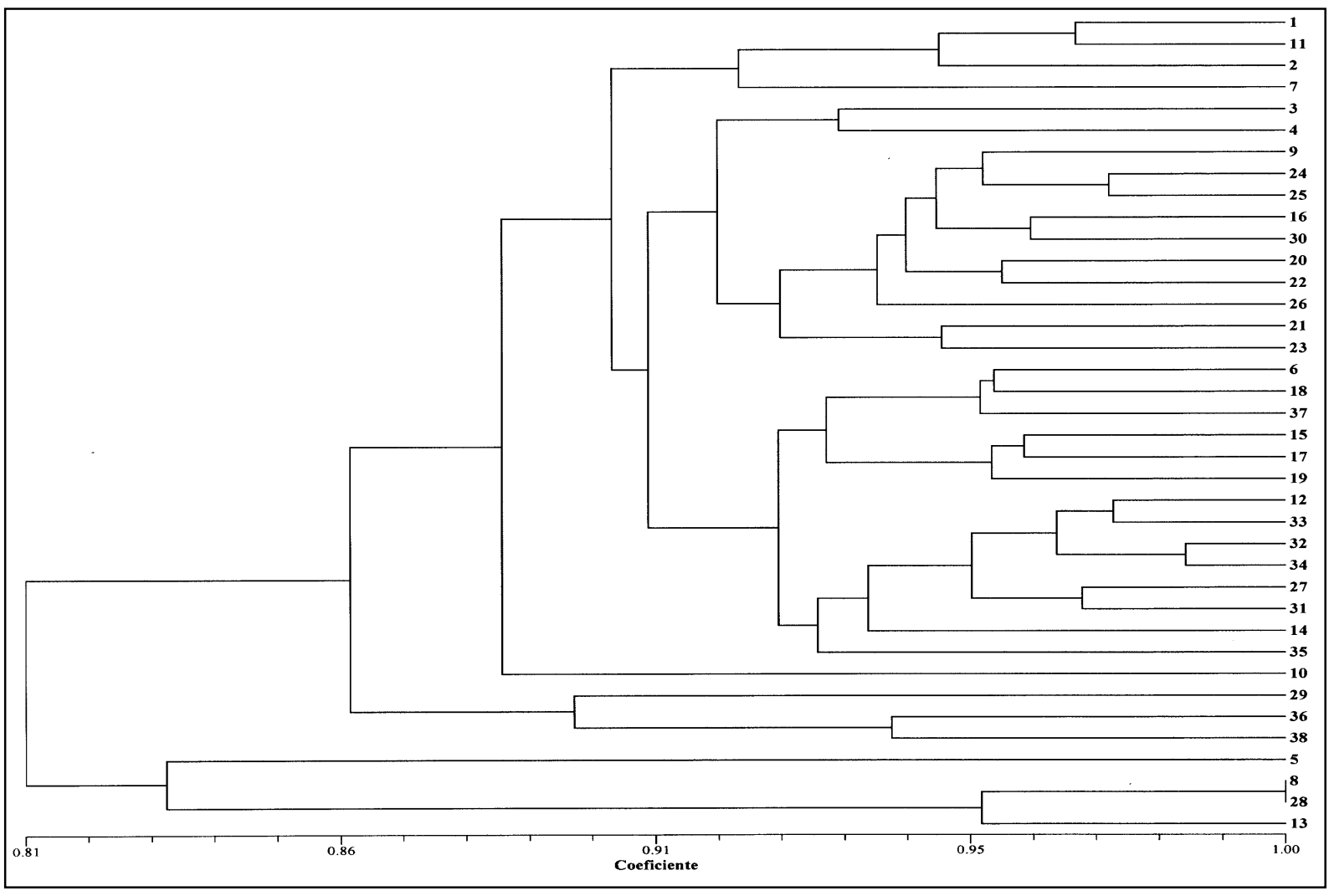

Figura 1 - Representação espacial, resultado da análise de RPDs, apresentando as relações existentes entre 25 acessos de erva-mate com tipo de folhas CL curta e larga.

tampão Tris-EDTA com RNAse, para degradação do RNA ficando, somente, o DNA genômico desejado.

\section{Condições da reação}

A técnica de RAPD (Random Amplified Polymorphic DNA) consiste na amplificação, mediante técnicas de PCR (Polymerase Chain Reaction), ao acaso, de fragmentos de DNA com uma série de oligonucleotídeos. As reações continham 1 unidade de Taq DNA polymerase (Biotools, Biotechnological \& Medical Laboratories, Madrid, Spain); 0,2 $\mu \mathrm{M}$ primer ou iniciador (British Columbia) (primers BC 512, 515, 518, 521, 538, 542, 543, 550, 551); 0,1mM dNTP (dNTP Master Mix, Ecogen srl, Ptge Dos de Maig, Barcelona, Spain); $75 \mathrm{mM}$ TrisHCl (pH=9,0), $2 \mathrm{mM} \mathrm{MgC} \ell_{2}, 50$ $\mathrm{mM} \mathrm{KCl}, 20 \mathrm{mM} \quad\left(\mathrm{NH}_{4}\right)_{2} \quad \mathrm{SO}_{4}, 0,001 \%$ BSA, concentração $1 \mathrm{x}$ (Biottols buffer); água esterilizada e $5,0 \mathrm{ng} / \mu \ell$ DNA em $25 \mu \ell$ de volume total. O PCR foi corrido usando um termociclador MJ Research, Inc, PTC-100 Programmable Thermal Controller (Watertown, Mass., USA) com ciclos térmicos programados de $2 \mathrm{~min}$ a $94^{\circ} \mathrm{C}$, seguido de 40 ciclos de $1 \mathrm{~min}$ a $92^{\circ} \mathrm{C}, 1 \mathrm{~min}$ a $35^{\circ} \mathrm{C}$ e $2 \mathrm{~min}$ a $72^{\circ} \mathrm{C}$, seguidos de $5 \mathrm{~min}$ a $72^{\circ} \mathrm{C}$. Foram feitos quarenta ciclos que duraram aproximadamente $5 \mathrm{~h}$. Completada a reação, as misturas foram mantidas em temperatura ambiente até análise em gel TBE de agarose a $1,5 \%$, corado com brometo de etídio e fotografado com filme de câmara Polaroid. Todos os experimentos foram duplicados, usando-se uma nova extração de DNA de $60 \%$ das novas amostras de folhas. Bandas não reproduzidas foram rejeitadas. A Análise estatística usou o programa NTSYS.

\section{RESULTADOS E DISCUSSÃO}

Na figura 1, representa-se a distribuição espacial dos 25 acessos de erva-mate que apresentam folhas do tipo CL (curta e larga). Notase a clara formação de 2 grupos distintos. Um grupo é formado pelos acessos 7, 8 e 15, e o outro grupo pelos demais acessos. Este resultado pode ser considerado dentro da normalidade, ainda que dentro de cada tipo de folha se esperasse maior uniformidade de distribuição, como a representada pela figura 2, na qual se tem a distribuição espacial dos 30 acessos de folhas de erva-mate do tipo LE (longa e estreita). GAUER \& CAVALLI-MOLINA 


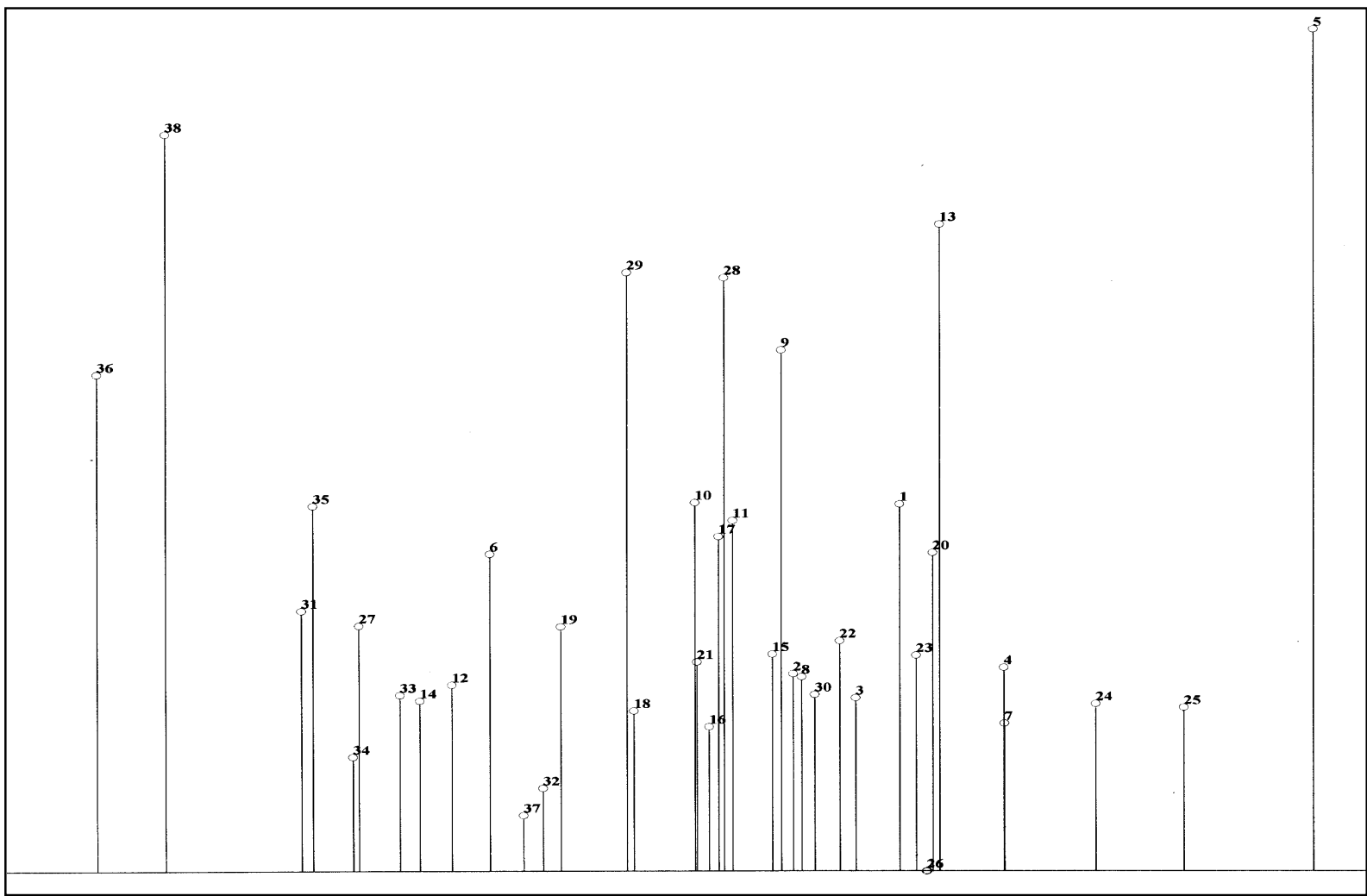

Figura 2 - Representação espacial, resultado da análise de RPDs, apresentando as relações existentes entre 30 acessos de erva-mate com tipo de folhas LE longa e estreita.

(2000), trabalhando com quatro populações naturais distintas de erva-mate, também obtiveram baixa diversidade genética entre populações. Além disso, a maior parte das bandas foi comum a todas populações e as bandas específicas ocorreram em baixas frequências. Assim como no presente estudo, este fato também ocorreu com outras espécies (WANG $\boldsymbol{e t}$ al., 1996).

Numa análise não tão rigorosa da figura 3, que apresenta o dendograma formado pelo resultado da análise de RAPDs, considerando os 25 acessos de folhas de erva-mate tipo CL e os 30 acessos do tipo LE, pode-se afirmar que foram formados três grupos de acessos. O primeiro grupo é representado em sua grande maioria por acessos com folhas tipo CL (19 acessos CL para 4 acessos LE), enquanto que o segundo grupo é basicamente composto por acessos com folhas tipo LE. No entanto, estes dois grupos se encontram no coeficiente de proximidade genética de 0,87 , aproximadamente. O terceiro e mais isolado grupo é formado por nove acessos, contendo folhas de ambos os tipos.

Este trabalho tentou buscar uma marca mais efetiva na caracterização de plantas naturais de erva-mate, que apresentavam distinto sabor na infusão de suas folhas. Ainda que diversos estudos tenham demonstrado considerável diferença entre espécies em nível de variação genética em populações naturais de plantas (HAMRICK, 1979), estes resultados sugerem que o número de iniciadores usados como marcadores moleculares neste experimento (9 "primers" gerando 168 bandas distintas), foram insuficientes para caracterizar geneticamente o caráter sabor em ervamate, embora apresente uma tendência de que o mesmo poderá ser obtido com o uso de uma maior série de iniciadores ou "primers". De qualquer maneira, o mesmo poderá não ocorrer e, portanto, para sanar esta dúvida, é recomendável dar continuidade ao referido estudo.

\section{CONCLUSÃO}

Existe um relativo agrupamento entre folhas de erva-mate do tipo CL (curta e larga) e LE (longa e estreita). No entanto, não é possível afirmar, com este estudo, se já existe um marcador molecular que identifique o caráter sabor de erva-mate. Sugerese continuar utilizando uma maior série de iniciadores como marcadores moleculares, buscando definir geneticamente este caráter.

Ciência Rural, v. 32, n. 3, 2002. 


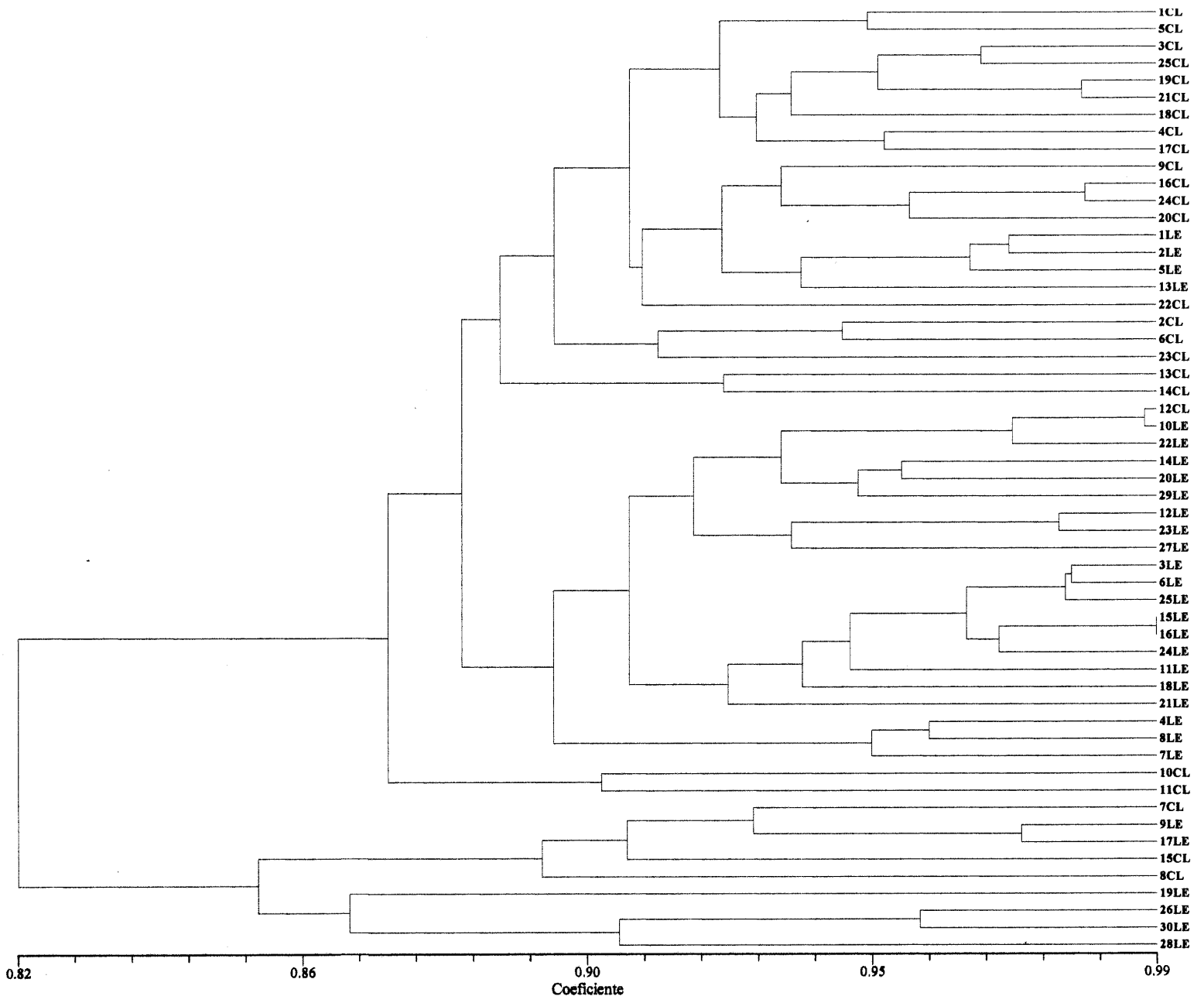

Figura 3 - Dendograma resultado da análise de RPDs, apresentando as relações existentes entre 25 acessos de folhas tipo CL e 30 acessos de folhas tipo LE de erva-mate.

\section{AGRADECIMENTOS}

Este trabalho só pôde ser realizado com o apoio financeiro da CAPES, da EPAGRI e do Departamento de Biología Vegetal da Escuela Tecnica Superior de Ingenieros Agrónomos da Universidad Politecnica de Madrid/Espanha, além do apoio de colegas. A todos, nossos agradecimentos.

\section{REFERÊNCIAS BIBLIOGRÁFICAS}

DA CROCE,D.M.; HIGA,A.R.; FLOSS,P.A. Escolha de fontes de sementes de erva-mate (Ilex paraguariensis St.Hil.) para Santa Catarina. Florianópolis : EPAGRI, 1994. 23p. (EPAGRI. Boletim Técnico, 69).

FERREIRA,M.E., GRATAPAGLIA,D. Introdução ao uso de marcadores RAPD e RFLP em análise genética. Brasília. EMBRAPA-CENARGEN, 1995. 221p.

FLOSS,P.A. Variações genéticas entre populaçoes naturais de Ilex paraguariensis St.Hil. (erva-mate) avaliados em Chapecó, SC e Três Barras, SC. Piracicaba, 1994. 94p. Dissertação
(Mestrado em Engenharia Florestal) - Universidade de São Paulo, 1994.

GAUER,L.; CAVALLI-MOLINA,S. Genetic variation in natural populations of maté (Ilex paraguariensis A. St.Hil., Aquifoliaceae) using RAPD markers. Heredity, v.84, p.647656,2000 .

GREGIANINI,T.S. Variabilidade de proteínas de reserva em populações naturais de erva-mate (Ilex paraguariensis St.Hil., Aquifoliaceae). Porto Alegre, 1999. 94p. Dissertação (mestrado) - Universidade Federal do Rio Grande do Sul, 1999.

HAMRICK,J.L. Gentic variation and longevity. In: SOLBRIG, O.T., JAIN,S.; JOHNSON,G.B.; et al. (eds.). Topics in plant population biology. New York : Columbia University, 1979. p.84-113.

VIDOR,M.A. \& BELÓ,A. Protocolo para extração de DNA de erva-mate (Ilex paraguariensis St.Hil.). In: CONGRESSO DE BIOTECNOLOGIA VEGETAL, 2000, Evora. Anais... Evora, Portugal : Universidade de Evora, 2000. N.i. 
WANG,C.T.; WANG,W.Y.; CHIANG,C.H.; $\boldsymbol{e t}$ al. Low genetic variation in Amentotaxus formosana Li revealed by isozyme analysis and random amplified polymorphic DNA markers. Heredity, v.77, p.388-395, 1996.

WILLIAMS,J.G.K., KUBELIK,A.R., LIVAK,K.J., et $\boldsymbol{a l}$. DNA polymorphisms amplified arbitrary primers are useful as genetic markers. Nucleic Acids Res, v.18, p.6531-6535,
1991.

WINGE,W.; WOLLHEIM,C.; CAVALLI-MOLINA,S., $\boldsymbol{e} \boldsymbol{t} \boldsymbol{a l}$. Variabilidade genética em populações nativas de ervamate e a implantação de bancos de germoplasma. In: WINGE,H., FERREIRA,A.G., MARIATH, J.E.A., et $\boldsymbol{a l}$. (eds). Erva-mate: Biologia e cultura no cone Sul. Porto Alegre : UFRGS, 1995. p.323-345. 